Article

\title{
Removal of Lead Ions from Aqueous Solutions by a Novel Ficus carica L.-Zeolite-Alginate Biocomposite
}

\author{
Meruyert KAYGUSUZ ${ }^{1}$ and Cem GÖK ${ }^{2, *}$ \\ 1 Pamukkale University, Denizli Vocational School of Technical Sciences, 20160, Denizli, Turkey \\ 2 Pamukkale University, Faculty of Technology, Metallurgical and Materials Engineering, 20020 Kinikli, \\ Denizli, Turkey \\ * Correspondence: cemgok2005@gmail.com; Tel.: +90-530-927-7696
}

\begin{abstract}
In this study, fig leaves, zeolite and alginate were used to prepare a biocomposite for the adsorption of $\mathrm{Pb}(\mathrm{II})$ ions from aqueous solutions. Effects of various parameters on the biosorption process such as $\mathrm{pH}$, temperature, initial lead concentration and contact time have been investigated. Maximum uptake of $\mathrm{Pb}$ (II) ions (85\%) has been achieved at $\mathrm{pH}$ 6, with $25 \mathrm{mg} / \mathrm{L}$ of initial concentration and at a temperature of $288.15 \mathrm{~K}$. Among the applied models, the data correlated well with Freundlich and D-R models and it was established that the biosorption was physical in nature. The amount of adsorbed lead per gram of sorbent was found to be $150.3 \mathrm{mg} / \mathrm{g}$. Thermodynamic parameters showed the exothermic heat of biosorption and the feasibility of the process. Results have suggested that the prepared biosorbent possesses promising biosorption potential.
\end{abstract}

Keywords: adsorption; lead; biocomposite; alginate; Ficus carica L.

\section{Introduction}

Among the heavy metals, lead is one of the major pollution sources which discharged into the environment from metal finishing, ceramics, pulp, lead smelters, electroplating, mining and battery manufacturing industries [1]. In addition, to provide best color matches and finishes textile and leather industries widely use pigments which contain mostly lead and cadmium [2]. Lead is a well-known highly toxic metal considered as a priority pollutant [3]. The presence of even low levels of lead in the environment may cause long-term health risks to humans and ecosystems. Therefore, it is necessary to remove the lead ions before they are released into the environment.

The removal of heavy metals from contaminated waters has been investigated employing a wide variety of methods including chemical precipitation, ion-exchange, membrane filtration, reverse osmosis, etc. Due to the expensive costs of the so-called methods, the most promising alternative method for the removal of metal ions is adsorption. There is a growing demand to find low-cost and efficient, locally available adsorbent for the adsorption of heavy metals.

In current study, biocomposite was prepared from natural materials such as zeolite, alginate and fig leaves. Fig (Ficus carica L.) is among the oldest fruits and is known to manhood from ancient times. F. carica L., belonging to the Moraceae family, is a deciduous tree native to South-western Asia and the Eastern Mediterranean [4]. Figs are an important traditional crop in Turkey, due to the wide adaptability to the soil and climatic conditions. Moreover, Turkey is a leader country in fig production in the world; hence, to evaluate the agricultural waste like fig leaves is noteworthy[5]. Natural zeolites have been known by their high ion-exchange capacity, relatively high specific surface areas and, more importantly, their relatively low prices[6]. Rich zeolite deposits, especially of clinoptilolite, are located in Turkey [7]; therefore, it is rational to benefit from this abundant material. The adsorptive properties of alginate based on the presence of carboxylic acid and hydroxyl functional groups that have a high affinity towards heavy metals. On the other hand, it is highly porous and allows an extended use of the surface [8]. 
In this study, the first attempt was to prepare biocomposite from fig leaves, zeolite and alginate; and benefit from not only the availability and low-cost of these compounds but also from the accumulative properties of fig leaves, the rigidity and thermal resistance of zeolite, and the high porosity and effective surface of alginate. In this regard, the main objective of the study was to investigate the use of environmentally friendly cost effective biocomposite to remove lead from aqueous media. For this purpose, the effects of various parameters on the adsorption process such as $\mathrm{pH}$, temperature, initial lead concentration and contact time have been investigated.

\section{Materials and Methods}

\subsection{Materials}

Zeolite and alginic acid sodium salt were purchased from Sigma-Aldrich (USA). Lead chloride $(\mathrm{PbCl} 2)$, hydrochloric acid $(\mathrm{HCl})$ and sodium hydroxide $(\mathrm{NaOH})$ were supplied from Merck (Germany).All chemicals used in the experiments were of analytical reagent grade.

\subsection{Preparation and characterization of biocomposite}

Harvested fresh Ficus carica L. leaf samples were extensively washed with tap and distilled water to remove impurities. Then, the leaf samples were dried at room temperature and not exposed to direct sunlight. The dried samples were ground in a mortar with pestle and sieved using a standard mesh $(<120 \mu \mathrm{m})$ sieve (Jeotest, Turkey). F. carica L. leaves powder and zeolite $(\sim 30 \mu \mathrm{m})$ were encapsulated into sodium alginate beads in aqueous calcium chloride solution to prepare a biocomposite material. For this purpose, a required amount of sodium alginate (\%2) was dissolved in $100 \mathrm{ml}$ distilled water with constant stirring at $50^{\circ} \mathrm{C}$ until a gelous solution was obtained. Zeolite $(0.5 \mathrm{~g})$ and F. carica L. leaves powder $(1 \mathrm{~g})$ were mixed carefully under continuous stirring until the mixture became homogeneous. The suspension was injected drop wise into a $0.5 \mathrm{M}$ solution of calcium chloride with the help of injection syringe. Fine biocomposite beads of alginate-zeolite-F. caricaL. leaves powder were formed. The hydrogel beads were separated from the solution by filtration and dried for overnight in an oven (Test, Turkey) maintained at $65^{\circ} \mathrm{C}$. The dried mass of the beads was used as a sorbent for lead ion removal. The dry weight is a value that is easy to standardize. In addition, taking into account the possible industrial applications this is relatively easy to transport and store the dried material.

Fourier Transform Infrared Spectroscopy (FTIR) was used to determine the vibration frequency changes in the functional groups of the prepared biocomposite. The FT-IR spectra within the range of wave-number of $4400-400 \mathrm{~cm}-1$ using $\mathrm{KBr}$ pressed disk technique were obtained by FTIR spectrometer(Agilent, USA).Scanning Electron Microscope (SEM) was used to analyze the surface properties and the morphology of the prepared biocomposite beads(Quanta FEG 250, USA).

\subsection{Batch experiments}

Stock solution of lead ions $(500 \mathrm{mg} / \mathrm{L}$ ) was prepared by dissolving calculated amount of $\mathrm{PbCl} 2$ in distilled water and working standards of required strength were prepared by diluting the reserve solution.

The adsorption experiments of lead with the prepared biocomposite were carried out by the batch equilibrium adsorption experiments using a thermostated shaker bath. Parameters such as $\mathrm{pH}$, initial concentration of lead solution, contact time and temperature were investigated. Most of the adsorption experiments were performed using the $0.1 \mathrm{~g}$ of biocomposite which was suspended in 25 $\mathrm{mL}$ of $\mathrm{PbCl} 2$ in a polyethylene (PE) flask at selected $\mathrm{pH}$. The $\mathrm{pH}$ was adjusted by adding the diluted $\mathrm{HCl}$ and $\mathrm{NaOH}$ to the solutions at the each experiment. The solution was separated from the solids by filtration after adsorption experiments. The lead concentration remained in aqueous solution was determined with inductively coupled plasma optic emission spectroscopy (ICP-OES, Spectro, Germany). 
The amount of adsorbed lead (qe, $\mathrm{mg} / \mathrm{g}$ ) was calculated by a mass balance relationship:

$$
\mathrm{q}_{\mathrm{e}}(\mathrm{mg} / \mathrm{g})=\frac{\left(\mathrm{C}_{\mathrm{i}}-C_{e}\right) V}{m}
$$

where $C_{i}$ and $C_{e}$ are the initial and equilibrium concentrations of lead ions $(\mathrm{mg} / \mathrm{L})$ in solutions, respectively. $\mathrm{m}$ is the weight of the sorbent $(\mathrm{g}), \mathrm{V}$ is the volume of the aqueous phase (L).

\subsection{Sorption Isotherms}

Langmuir, Freundlich and Dubinin-Radushkevich-Kaganer (DRK) isotherms are applied to describe the sorption characteristics of $\mathrm{Pb}$ (II) on the sorbent.

\subsubsection{Langmuir isotherm}

The Langmuir isotherm is the most widely used model and traditionally used to quantify and contrast the performance of different sorbents. This model's theory presumed monolayer coverage of adsorbate over a homogeneous sorbent surface [9]. Langmuir model linearized equation is expressed as follows:

$$
\frac{C_{e}}{q_{e}}=\frac{1}{Q_{0} b_{L}}+\frac{\mathrm{C}_{\mathrm{e}}}{Q_{0}}
$$

where $\mathrm{q}_{\mathrm{e}}$ is the amount of metal ions adsorbed onto adsorbent, $\mathrm{C}_{\mathrm{e}}$ is the equilibrium concentration of lead in solution, and $\mathrm{Q}_{0}$ and $\mathrm{b}_{\mathrm{L}}$ are Langmuir constants related to adsorption capacity and adsorption energy, respectively.

\subsubsection{Freundlich isotherm}

The Freundlich model assumes a logarithmic decrease in the enthalpy of adsorption with the increase in the fraction of occupied sites. In other words, this model is also an empirical expression encompassing the surface heterogeneity and the exponential distribution of active sites and their energies [10]. This model can be given as follows:

$$
\log q_{e}=\log K_{F}+\frac{1}{n_{F}} \log C_{e}
$$

where $\mathrm{K}_{\mathrm{F}}$ represents the adsorption capacity $(\mathrm{mg} / \mathrm{g}), \mathrm{n}_{\mathrm{F}}$ is a constant related to adsorption intensity (dimensionless).

\subsubsection{Dubinin-Radushkevich (D-R) isotherm}

The other widely used isotherm is Dubinin-Radushkevich (D-R) model, used to estimate the apparent free energy of adsorption, was proposed an equation to find out the adsorption mechanism on the basis of the potential theory assuming a heterogeneous surface [11]. The linearized equation of the D-R isotherm is given as:

$$
\ln C_{a d s}=\ln X_{\mathrm{m}}-\beta \varepsilon^{2}
$$

where Cads $(\mathrm{mmol} / \mathrm{g})$ is the amount of solute sorbed per unit weight of solid, $\mathrm{Xm}(\mathrm{mg} / \mathrm{g})$ is the adsorption capacity, $\beta(\mathrm{mol} / \mathrm{K})$ is a constant related to energy and $\varepsilon$ is the Polanyi potential. Polanyi potential can be computed by following equation:

$$
\varepsilon=R T \ln \left(\frac{1}{1+C_{e}}\right)
$$

where $\mathrm{R}$ is a gas constant in $\mathrm{kJ} / \mathrm{mol} \mathrm{K}$ and $\mathrm{T}$ is the temperature in Kelvin. If $\operatorname{lnCads}$ is plotted against $\varepsilon 2, \beta$ and $X m$ can be obtained from the slope and intercept, respectively. The mean energy of adsorption (E) is calculated by the following equation using the constant $\beta$.

$$
E=\frac{1}{\sqrt{-2 \beta}}
$$


142

143

144

145

146

147

148

149

\section{Results and Discussion}

\subsection{Characterization of the biocomposite}

The images of the dried and powdered fig leaves, the as-prepared and dried biocomposite are given in Figure 1. As it could be seen from Fig. 1, the prepared biocomposite beads have characteristic green color which came from the fig leaves origin and became darker after drying. The biocomposite beads appeared spherical in shape and uniform insize (diameter $2 \mathrm{~mm}$ ) which reduced with drying $(\sim 0,5 \mathrm{~mm})$. However, the specific characteristic of the alginate beads is to swell repeatedly to the previous size in the liquid media.

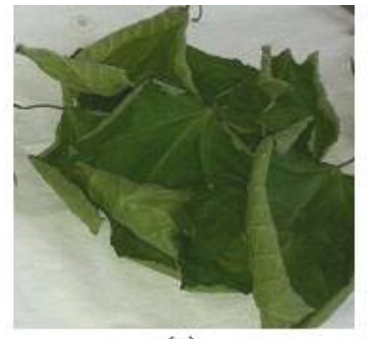

(a)

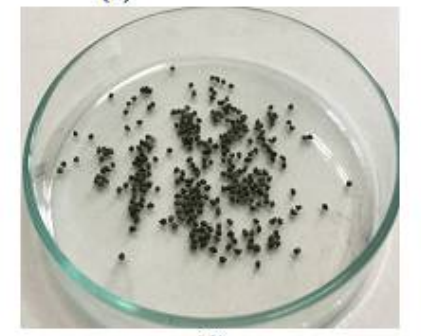

(d)

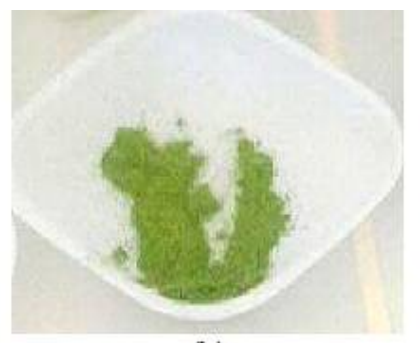

(b)

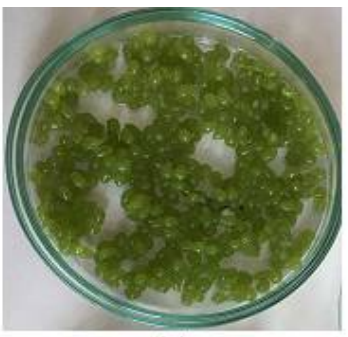

(c)

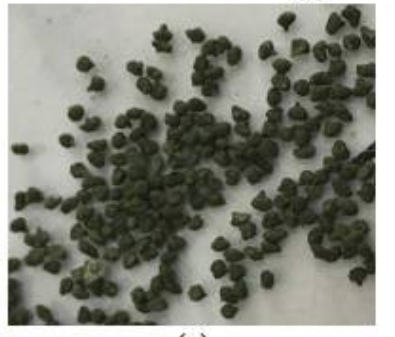

(e)

Figure 1. Dried (a) and powdered fig leaves (b), the as-prepared and dried (c, d, e) biocomposite.

\subsubsection{FT-IR Analysis}

F. carica-zeolite-alginate biocomposite was analyzed using a Fourier transform infrared spectrometer as shown in Figure 2. The absorption peak at $3375 \mathrm{~cm}-1$ and $3245 \mathrm{~cm}-1$ indicated the presence of both free and hydrogen-bonded $-\mathrm{OH}$ groups on the surface of the biocomposite. The other peaks observed at 1602, 1077, and $940 \mathrm{~cm}-1$ may be due to C-C, C-O, and C-N stretching, respectively [12]. The peak at $821 \mathrm{~cm}-1$ indicates the presence of $-\mathrm{OH}$ bending due to $\beta$-glycosidic linkage. The appearance of smaller peaks at 1314 and $1008 \mathrm{~cm}^{-1}$ may be attributed to $-\mathrm{CH}$ and to aromatic $\mathrm{CH} 2$ bending which originates probably from the lignin content of the fig leaves [13,14]. The hydrogel displays absorbance peaks of COOH at $1429 \mathrm{~cm}-1$ [15]. The peaks located at 1112 and $1147 \mathrm{~cm}^{-1}$ can be assigned to stretching vibration of C-O-C bond of carbohydrate as polysaccharide which is attributed to the alginic acid [16]. It was supposed that immobilization of zeolite and fig leaves into the alginate beads reduced the binding efficiency of the active sites of alginate, which was resulted in the physical adsorption of lead in this study. 
165

Figure 2. The Fourier Transform Infrared Spectroscopy spectra of biocomposite.

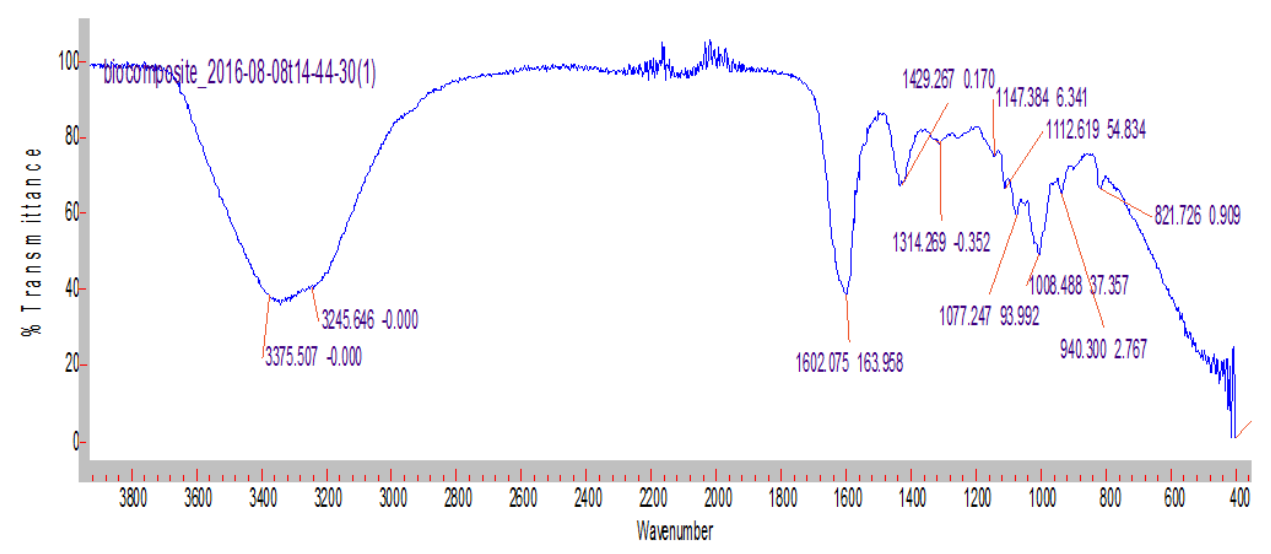

\subsubsection{SEM Analysis}

The microscopic images obtained by a scanning electron microscope clearly depicted the surface topography and internal architecture of the sorbent (Figure 3). The prepared biocomposite bead has irregular and porous structure with latitudinal cavities. When the surface morphology was examined under power of magnification 2500x a lot of pores and wrinkles were appeared. Encapsulated fig leaves powder and zeolite were seen as stretched to the alginate matrix and it changed the morphology of surface due to grafting of the matrix with the amorphous and crystalline particles of fig leaves and zeolite, respectively. This led to simultaneous physical and chemical cross-linking in the biocomposite structure which was supported by FTIR findings and presumably affected the adsorption process.

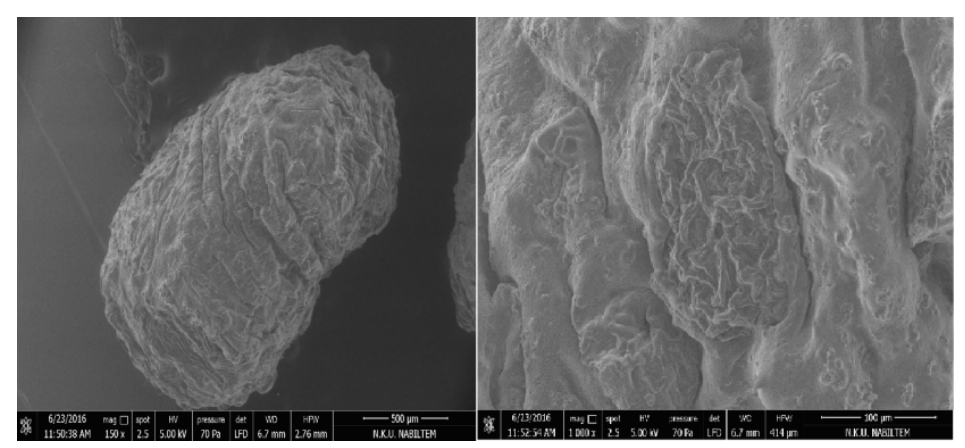

Figure 3. SEM micrographs of the prepared biocomposite.

\subsection{Studies on optimum removal conditions}

In order to compare the efficiency of the prepared biocomposite, the adsorption of lead ions were performed using separately F. carica L leaves powder, zeolite and alginate. The batch adsorption experiments were investigated under the conditions of $0.1 \mathrm{~g}$ of sorbent, $25 \mathrm{~mL}$ and $100 \mathrm{mg} / \mathrm{L}$ of lead solution at $\mathrm{pH} 4,25^{\circ} \mathrm{C}$ for $2 \mathrm{~h}$ at $200 \mathrm{rpm}$ agitation speed. The obtained results show that adsorption capacities of F. carica L leaves powder, zeolite and alginate were $24 \%, 18 \%$ and $12 \%$, respectively. However, at the same conditions maximum uptake of lead ions by the biocomposite was $40 \%$.

\subsubsection{Effect of initial $\mathrm{pH}$}

$\mathrm{pH}$ has been known as an important parameter affecting the sorption process. In order to determine the effect of $\mathrm{pH}$ on the adsorption of $\mathrm{Pb}(\mathrm{II})$ ions onto biocomposite, the batch adsorption studies at different $\mathrm{pH}$ values were carried out. Experiments were investigated under the conditions 
191 192

193

194

195

196

197

198

199

200

201

202

203 of $0.1 \mathrm{~g}$ of sorbent, $25 \mathrm{~mL}$ and $10 \mathrm{mg} / \mathrm{L}$ of lead solution at $25{ }^{\circ} \mathrm{C}$ for $2 \mathrm{~h}$ at $200 \mathrm{rpm}$ agitation speed. Figure 4 shows that lead removal changes in a $\mathrm{pH}$ range of $2-8$.

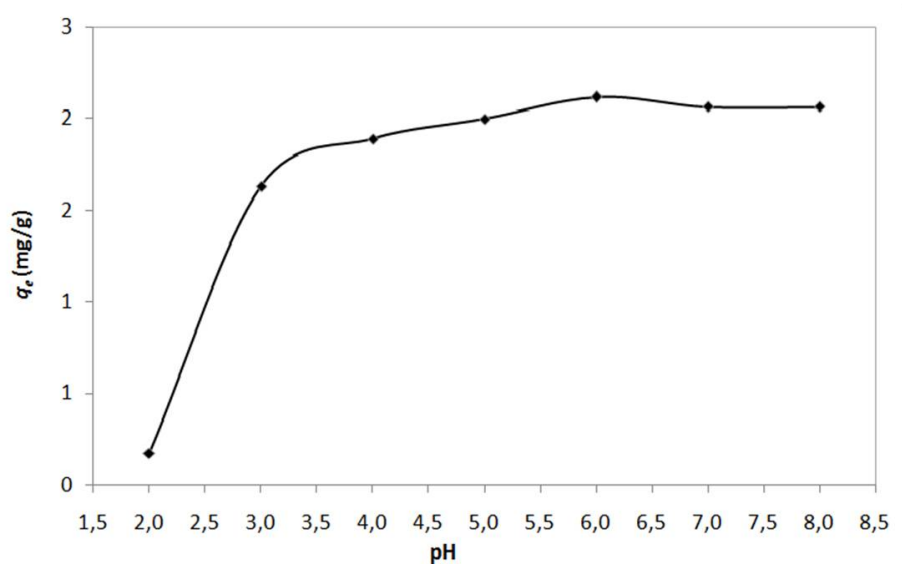

Figure 4. The adsorbed lead efficiency as a function of $\mathrm{pH}$.

As can be seen from the Figure 4, the maximum adsorption of $\mathrm{Pb}$ (II) ions on the sorbent was observed at $\mathrm{pH} 6.00$ with 85\%.After this $\mathrm{pH}$ a slight decrease in the adsorption process was determined. At low $\mathrm{pH}$, competition for metal binding sites between metal ions and hydrogen $(\mathrm{H}+)$ ions has been established so that $\mathrm{Pb}$ removal showed a lower metal uptake due to the predominance of hydrogen ions [17]. As the $\mathrm{pH}$ increases, this competitive effect is minimized and the sorbent surface became deprotonated and negatively charged, which resulted in increasing binding of $\mathrm{Pb}$. Based on these facts, it can be admitted that the optimum $\mathrm{pH}$ value for $\mathrm{Pb}$ adsorption by biocomposite was at pH 6 (Figure 4). Thus, the further experiments were performed at this $\mathrm{pH}$.

\subsubsection{The effect of initial $\mathrm{Pb}$ (II) concentration}

The adsorption of $\mathrm{Pb}(\mathrm{II})$ was studied as a function of initial $\mathrm{Pb}(\mathrm{II})$ concentration. Adsorption efficiencies of the biocomposite as a function of the initial concentration of lead between 5 and 200 $\mathrm{mg} / \mathrm{L}$ were presented in Figure 5. The adsorption experiments were carried out under the conditions of $\mathrm{pH} 6.0,0.1 \mathrm{~g}$ of sorbent, $25 \mathrm{~mL}$ of lead solution, $25{ }^{\circ} \mathrm{C}$ temperature, $2 \mathrm{~h}$ of contact time at $200 \mathrm{rpm}$ agitation speed.

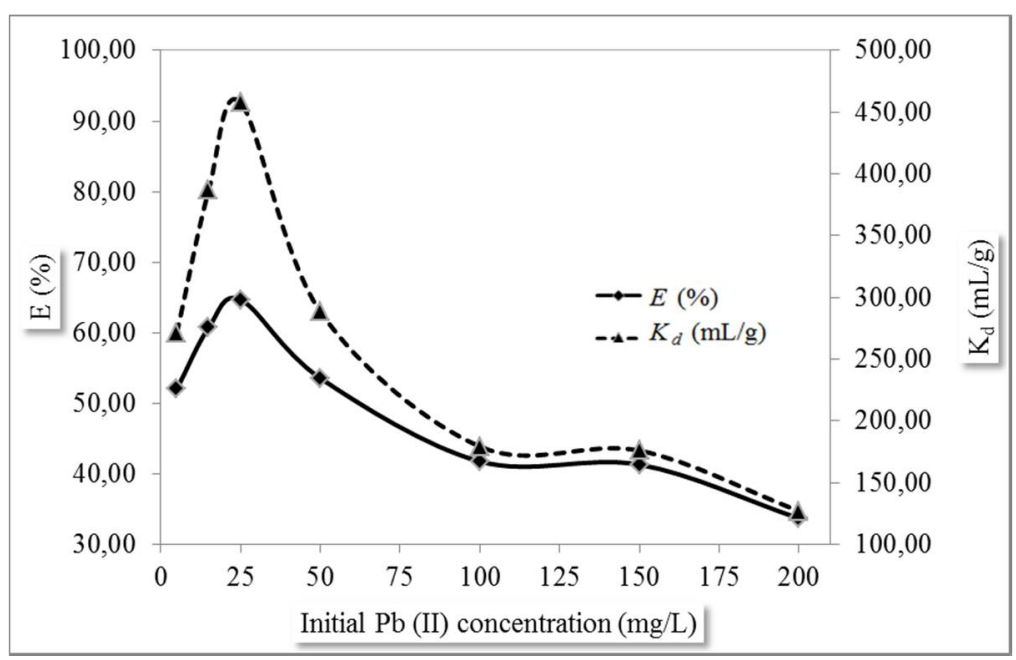

Figure 5. The adsorbed lead efficiency as a function of initial $\mathrm{Pb}(\mathrm{II})$ concentration.

As seen in Figure 5, the $\mathrm{Pb}$ (II) sorption increased from 52.0 to $64.7 \%$ with an increase of the initial lead concentration in solution from 5 to $25 \mathrm{mg} / \mathrm{L}$ and then decreased to $33.70 \%$ at $200 \mathrm{mg} / \mathrm{L}$ of lead concentration. As noticed the adsorption efficiency decreases by increasing $\mathrm{Pb}$ (II) concentration 
214 in solution. The biocomposite has a maximum lead sorption at $25 \mathrm{mg} / \mathrm{L}$ initial lead concentration. 215 With the increase of metal ion concentration, the binding sites on the surface of the biosorbent 216 become saturated [18] and, hence, are no longer capable to remove $\mathrm{Pb}$ ions from media.

\subsubsection{Effect of contact time}

The contact time between the metal ions and biocomposite has great importance for designing adsorption processes. The effect of contact time on the lead adsorption in the range of 30-720 min was investigated with $25 \mathrm{~mL}$ and $100 \mathrm{mg} / \mathrm{L}$ of lead solution, $0.1 \mathrm{~g}$ of the sorbent at $\mathrm{pH} 6.0,25^{\circ} \mathrm{C}$ at $200 \mathrm{rpm}$ agitation speed. Figure 6 shows adsorbed lead efficiency as a function of contact time.

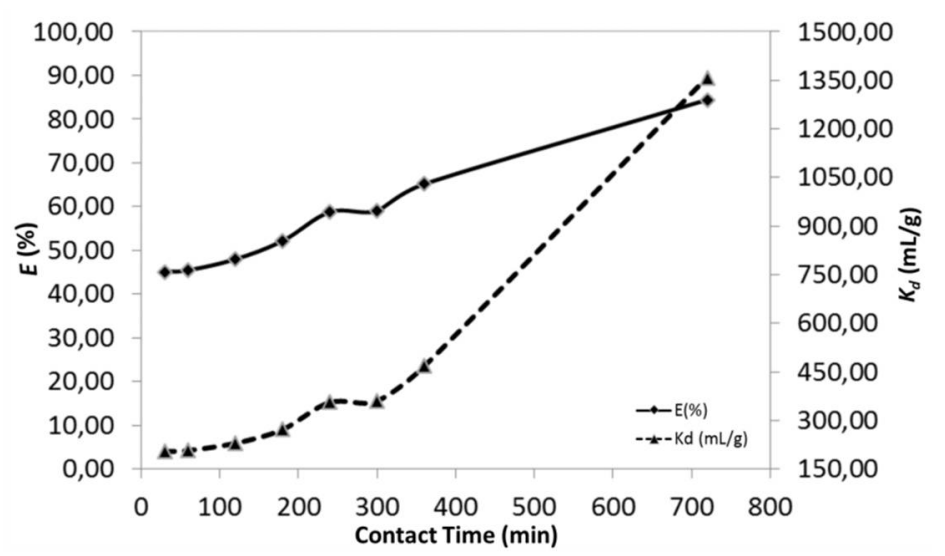

Figure 6. The adsorbed lead efficiency as a function of contact time.

As clearly seen from Figure 6, high removal percentage of lead is obtained even at the beginning of the sorption. The adsorption efficiency increases rapidly over $65 \%$ at the first $360 \mathrm{~min}$. After 720 minutes, nearly $85 \%$ of lead ions have been removed from the solution. As the contact time increased the active sites on the sorbent were filled.

\subsubsection{Effect of temperature and thermodynamic studies}

The effect of temperature on the adsorption of $\mathrm{Pb}(\mathrm{II})$ was studied varying 5 different temperature from 288.15 to $328.15 \mathrm{~K}$ while the other parameters were kept constant $(0.1 \mathrm{~g}$ of biocomposite in $25 \mathrm{~mL}$ and $50 \mathrm{mg} / \mathrm{L}$ of standard lead solution at $\mathrm{pH} 6.0$ and $2 \mathrm{~h}$ of contact time at 200rpm agitation speed).The influence of different temperatures on adsorption of lead ions on the biocomposite was examined and it was appeared to be temperature dependent over the temperature range tested as shown in Figure 7. According to results, adsorption of lead ions was exothermic in nature.

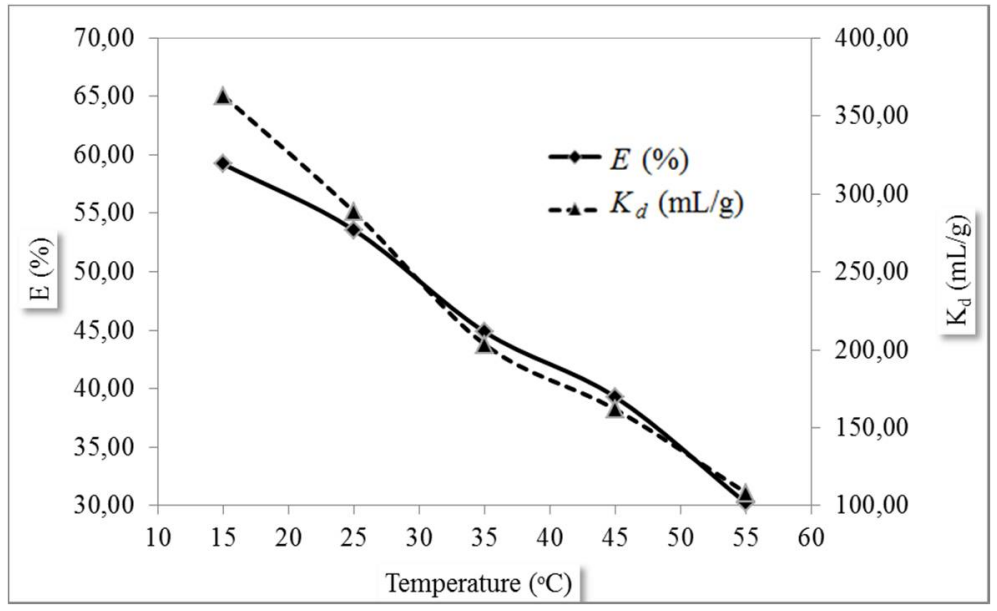


Figure 7. The adsorbed lead efficiency as a function of temperature.

Thermodynamic parameters (enthalpy, $\Delta \mathrm{H}^{\circ}$, entropy, $\Delta S^{\circ}$, Gibbs energy change, $\Delta \mathrm{G}^{\circ}$ ) were calculated by using the following equation:

$$
\ln K_{\mathrm{d}}=\left(\frac{\Delta S_{\mathrm{ads}}^{\mathrm{o}}}{R}\right)-\left(\frac{\Delta H_{\mathrm{ads}}^{\mathrm{o}}}{R T}\right)
$$

where $\mathrm{K}_{\mathrm{d}}$ is distribution coefficient, $\mathrm{R}$ is the gas constant $(8.314 \mathrm{~J} / \mathrm{molK}), \mathrm{T}$ is temperature in Kelvin, $\Delta H_{\mathrm{ads}}^{\mathrm{o}}, \Delta S_{\mathrm{ads}}^{\mathrm{o}}$, and $\mathrm{T}$ are the enthalpy and entropy, respectively. The plot of $\ln \mathrm{K}_{\mathrm{d}}$ against $1 / \mathrm{T}$ is created and the values of enthalpy and entropy were obtained from the slope and intercept of the plot (Figure 8). The following well-known equation was used to calculate Gibbs free energy:

$$
\Delta G=\Delta H-T \Delta S
$$

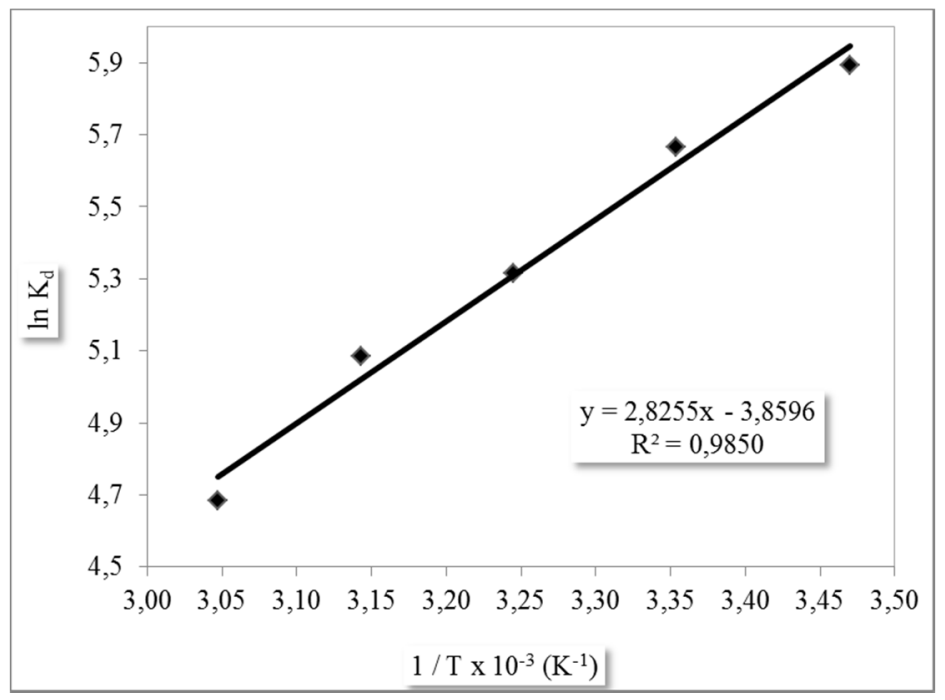

Figure 8. Influence of temperature on the thermodynamic behaviour of biosorption of $\mathrm{Pb}(\mathrm{II})$ on biocomposite.

The negative value of enthalpy change, $\Delta \mathrm{H}$, shows that the adsorption of lead is exothermic process. The value of $\Delta \mathrm{G}$ for these processes becomes less negative with increasing temperature which shows that sorption is less favored at high temperatures as shown in Table 1 . The reaction is spontaneous and more favorable at lower temperatures. The negative value of adsorption entropy is a harmonious result with the general information of decreasing entropy when ions pass solid phase from solution.

Table 1. Thermodynamic parameters for the adsorption of $\mathrm{Pb}(\mathrm{II})$.

\begin{tabular}{cccccccc}
\hline \multirow{2}{*}{$\Delta \mathbf{H}^{\circ}$} & \multirow{2}{*}{$\boldsymbol{\Delta} \mathbf{S}^{\circ}$} & \multicolumn{5}{c}{$\Delta \mathbf{G}^{\circ}(\mathbf{k J} / \mathbf{m o l})$} \\
\cline { 4 - 8 } $\mathbf{( k J / m o l )}$ & $\mathbf{( J / m o l K )}$ & $\mathbf{R}^{2}$ & $288.15 \mathrm{~K}$ & $298.15 \mathrm{~K}$ & $308.15 \mathrm{~K}$ & $318.15 \mathrm{~K}$ & $323.15 \mathrm{~K}$ \\
\hline-23.491 & -32.089 & 0.9850 & -14.245 & -13.924 & -13.603 & -13.282 & -12.961 \\
\hline
\end{tabular}

\subsection{Adsorption Isotherms}

To acquire more insight into the adsorption of lead on to alginate-zeolite-F.carica L. biocomposite, the results of equilibrium batch sorption experiments were evaluated with isotherm models. The adsorption of lead on to biocomposite is a mass transfer operation that can be described mathematically. The equilibrium is established between the concentration of the metal ions 
264

dissolved in aqueous phase and that bound to the adsorbent [19, 20]. In order to analyze this process, the experimental data have been subjected to different sorption isotherms namely Freundlich, Langmuir and Dubinin-Radushkhevich models. Adsorption equilibrium in the concentration range of 5-200 mg/L was studied with $100 \mathrm{mg}$ of alginate-zeolite-F. carica L. biocomposite at $25^{\circ} \mathrm{C}, \mathrm{pH} 6.0$ and 120 min contact time. The constants and correlation coefficients (R2) of isotherm models have been calculated from the plots for adsorption of lead on the biocomposite and the results are given in Table 2.

Table 2. Constants of isotherm models for lead adsorption onto biocomposite.

\begin{tabular}{ccc}
\hline Isotherm models & \multicolumn{2}{c}{ Parameters } \\
\hline Langmuir & $Q_{o}(\mathrm{mg} / \mathrm{g})$ & 370,4 \\
& $b_{L}(\mathrm{~L} / \mathrm{mg})$ & 0,006 \\
& $R^{2}$ & 0.8324 \\
\hline Freundlich & $K_{F}(\mathrm{mg} / \mathrm{g})$ & 2.68 \\
& $n_{F}$ & 1.16 \\
& $R^{2}$ & 0.9845 \\
\hline Dubinin-Radushkevich & $X_{m}(\mathrm{mg} / \mathrm{g})$ & 150,3 \\
& $\beta(\mathrm{mol} / \mathrm{kJ})$ & $2,97 \times 10^{-8}$ \\
& $E(\mathrm{~kJ} / \mathrm{mol})$ & 4,10 \\
& $R^{2}$ & 0.9817 \\
\hline
\end{tabular}

3.3.1. Langmuir Isotherm

The equilibrium data for $\mathrm{Pb}(\mathrm{II})$ ions over the concentration range from 5 to $200 \mathrm{mg} / \mathrm{L}$ at $298.15 \mathrm{~K}$ has been correlated with the Langmuir isotherm (Figure 9). $\mathrm{Q}_{0}$ and bLwere calculated from the slope and intercept of linear plots of Ce/qe versus Ce. Considering the comparative magnitudes of correlation coefficients together with the isotherm constants suggests that the Langmuir isotherm does not provide a particularly good model for the adsorption of lead. Thus, the behavior of lead adsorption onto biocomposite does not follow much to the Langmuir isotherm.

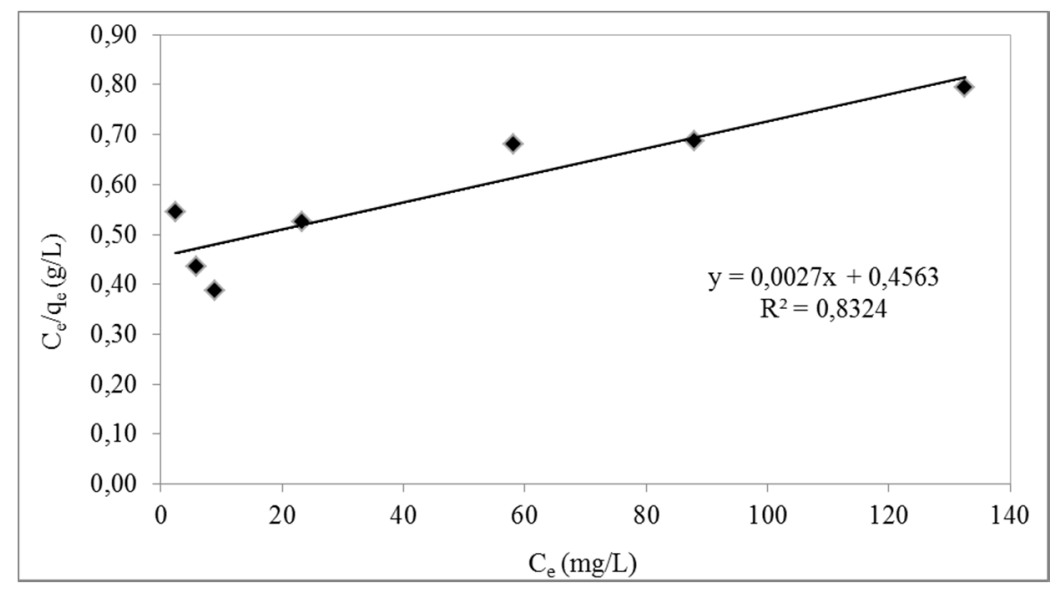


Figure 9. Linear isotherm model of Langmuir for lead biosorption on alginate-zeolite-Ficus carica L. biocomposite.

\subsubsection{Freundlich Isotherm}

Linear plot of logqe versus logCe shows the applicability of Freundlich isotherm for lead adsorption onto biocomposite (Figure 10). According to the correlation coefficients, the adsorption process could be well described by Freundlich equation. The values of $n$ are bigger than 1 , reflecting the beneficial adsorption. The numerical value of $1 / \mathrm{n}<1$ indicates that sorption capacity is only slightly suppressed at lower equilibrium concentration and suggests multiple binding sites, with the highest strength sites binding the sorbate first. This isotherm predicts saturation of the sorbent by the sorbate thus infinite surface coverage is predicted mathematically, indicating a multilayer sorption of the surface [21]. The value of KF, which signify the sorption capacity, is calculated as 2.68 $\mathrm{mg} / \mathrm{g}$. Although the adsorption process can be described well by Freundlich equation according to the correlation coefficient, the obtained result was observed to be incompatible with the measured adsorption capacity obtained by experiments.

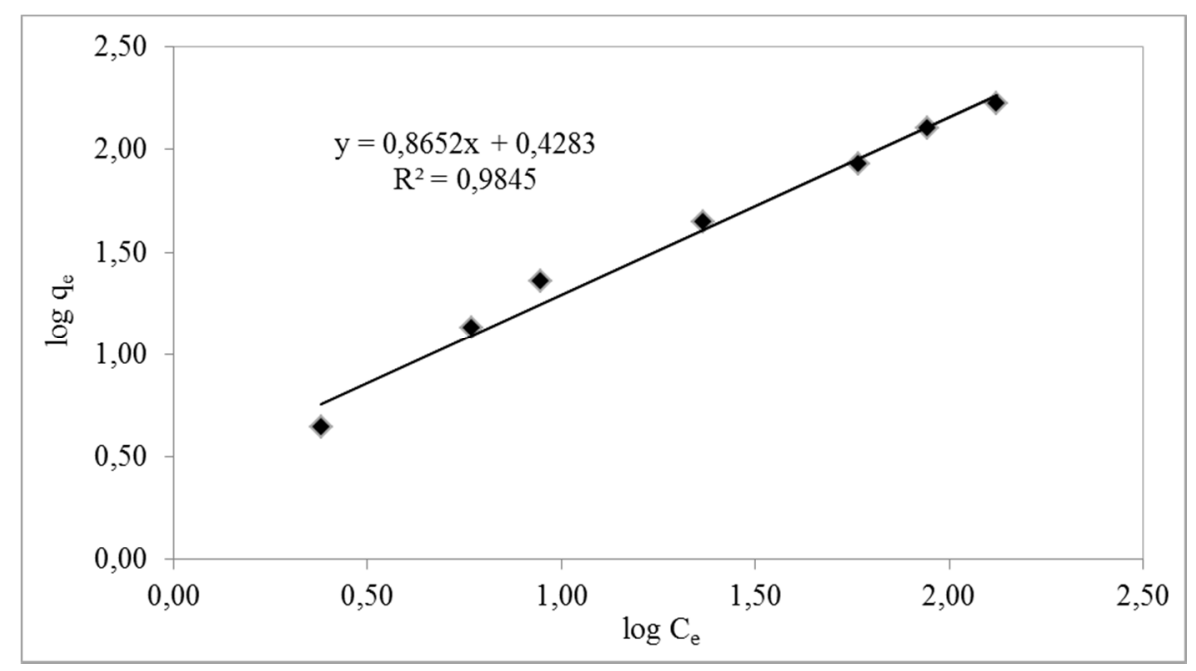

Figure 10. Linear isotherm model of Freundlich for lead biosorption on alginate-zeolite-Ficus carica L. biocomposite.

\subsubsection{Dubinin-Radushkevich-Kaganer (DRK) isotherm}

The plot of $\ln$ Cads against $\varepsilon^{2}$ is a straight line as shown in Figure 11. $\beta$ and $\mathrm{Xm}$ can be obtained from the slope and intercept, respectively. The calculated constants of Dubinin-Radushkevich isotherm and mean free energies are given in Table 2 . The adsorption capacity $(\mathrm{Xm})$ of the D-R model is $150.3 \mathrm{mg} / \mathrm{g}$ for lead ions. It is expected for this amount to be very close to the measured adsorption capacity that was obtained by adsorption experiments. The magnitude of $\mathrm{E}$ is used to estimate the reaction mechanism of adsorption process. If value of $E$ is between 1 and $8 \mathrm{~kJ} / \mathrm{mol}$, it indicates a physical adsorption. If value of $\mathrm{E}$ is higher than $8 \mathrm{~kJ} / \mathrm{mol}$, the adsorption process is of a chemical nature. Hence, the value of $\mathrm{E}, 4.10 \mathrm{~kJ} / \mathrm{mol}$ shows that the process is in the range of physical adsorption.

Thus, the fact that the lead equilibrium data fits well within both Freundlich and DRK isotherm models suggests that $\mathrm{Pb}$ adsorption onto biocomposite is of a heterogeneous nature. The heterogeneous structure of the prepared biocomposite was also accomplished by SEM images. Besides, the good fit of the DRK isotherm, with $\mathrm{R}^{2}$ value greater than 0.9 , suggests that this isotherm could be more appropriate under industrial conditions [22]. 


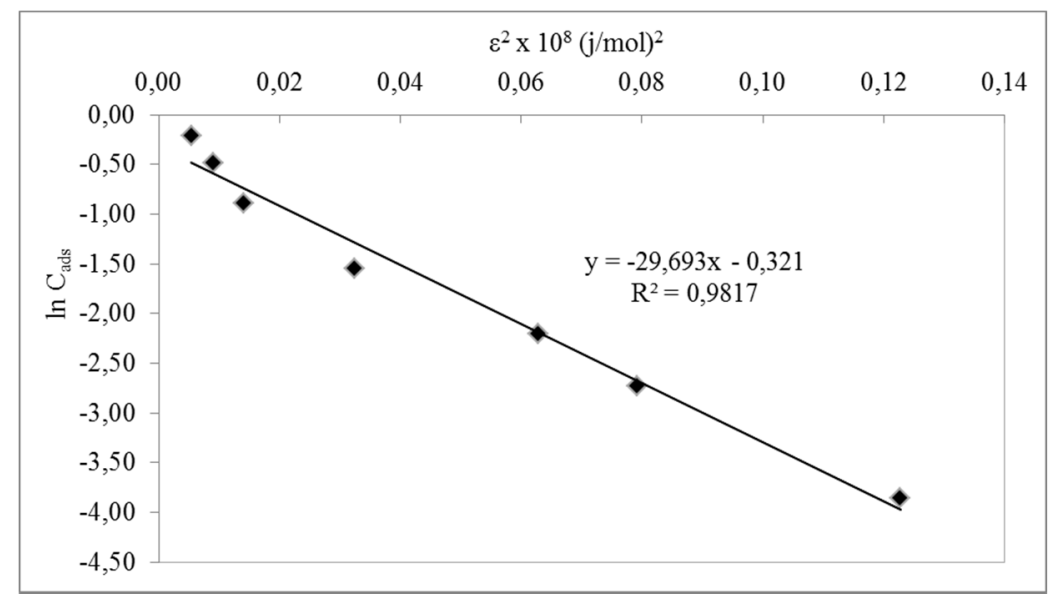

Figure 11. Linear isotherm model of Dubinin-Radushkevich (D-R) for lead biosorption on alginate-zeolite-Ficus carica L. biocomposite.

3.4. Comparison of alginate-zeolite-F.carica L. biocomposite with other biosorbents

Various studies have been performed on the adsorption of lead in literature for recent years. A comparison of the lead metal uptake capacities of this study with those of other biosorbents reported in the literature is given in Table 3. Although a direct comparison of the results of our study with other reported biosorbents is difficult due to the varying experimental conditions employed in those studies, in general, alginate-zeolite-F.carica L. biocomposite exhibited reasonable adsorption capacity in comparison with those biosorbents.

Table 3. Comparison of lead uptake capacities ( $\mathrm{mg} / \mathrm{g}$ ) of various biosorbents.

\begin{tabular}{lcl}
\hline \multicolumn{1}{c}{ Biosorbent } & $\begin{array}{c}\text { Maximum } \\
\text { uptake (mg/g) }\end{array}$ & References \\
\hline Olive stone waste & 9.30 & {$[23]$} \\
Sulfured orange peel (MOP) & 164.0 & {$[24]$} \\
Cinnamomum camphora leaves & 73.15 & {$[25]$} \\
Modified lentil husk & 81.43 & {$[26]$} \\
Australian marine algae & 322 & {$[27]$} \\
Tea waste & 65.0 & {$[28]$} \\
Green algae & 140.84 & {$[29]$} \\
Alginate-zeolite-F. carica L. biocomposite & 150.31 & Present study \\
\hline
\end{tabular}

The last few decades, development of new low cost biosorbents that have metal binding capacities and modification of the performance of existing ones has been intensified. Plants have been known by their heavy metal accumulation properties and have recognized as bioindicators. The study was performed under heavy metal accumulation level of F. carica bark and leaves [4]. The removal efficiency of $31.02 \%$ was reached when raw F. carica leaves were used for the removal of $\mathrm{Co}$ (II) and it was found that the treatment of the leaves with $\mathrm{MgCl} 2$ caused an increase in the removal efficiency (57.15\%) [18]. F. carica bastfiber was used for the adsorption of $\mathrm{Cr}(\mathrm{VI})$ and maximum adsorption capacity was found as $19.68 \mathrm{mg} / \mathrm{g}$ [30]. Sharma et al. (2013) chemically modified the F. carica bastfiber with acrylic acid and found $56 \%$ of adsorption of $\mathrm{Cr}(\mathrm{VI})$ for this sorbent. Sasikala and Muthuraman (2015) used F. carica seeds for the adsorption of $\mathrm{Cr}$ (III) and found the average percentage of adsorption as $94.6 \%$ that indicated the occurrence of a strong interaction 
To the best of our knowledge, there is no study performed on the adsorption of lead ions on the biocomposite containing F. carica L. leaf powder. The use of F. carica L. leaf powder in combination with zeolite in the alginate beads lowers the amount of alginate necessary for adsorption, resulting in lower cost. Moreover, the biodegradability of F. carica can contribute to a hale and hearty ecosystem and their low cost and reasonable performance can fulfill the economic interest of various industries.

\section{Conclusions}

Natural adsorbents are basically biodegradable that consists mainly of degradable organic matter. The prepared biocomposite in this study was consisted of natural materials such as fig leaves, alginate and zeolite. The adsorption process was lead ion concentration and $\mathrm{pH}$ dependent. The maximum adsorption of $\mathrm{Pb}(\mathrm{II})$ ions on the biocomposite was observed $85 \%$ at $\mathrm{pH} 6.0$ with $25 \mathrm{mg} / \mathrm{L}$ initial $\mathrm{Pb}(\mathrm{II})$ concentration. This $\mathrm{pH}$ is appropriate for the treatment of wastewater where $\mathrm{Pb}$ (II) concentration can be found in the diluted form. The negative value of enthalpy change $\Delta H$ $(-23.491 \mathrm{~kJ} / \mathrm{mol} \mathrm{K})$, shows that the adsorption of lead is exothermic process. The reaction is spontaneous and more favorable at lower temperatures. The equilibrium data for biocomposite were fitted well with the Freundlich and D-R isotherm models, suggesting that the multilayer adsorption of $\mathrm{Pb}$ (II) ion occurred on the heterogeneous surface of the beads. Thetheoretical value of the sorption capacity $\left(\mathrm{X}_{\mathrm{m}}\right)$ is founded as $150.3 \mathrm{mg} / \mathrm{g}$. The mean energy of adsorption calculated as $4.10 \mathrm{~kJ} / \mathrm{mol}$ shows that the process is in the range of physical adsorption. The results of present study have suggested that the prepared biocomposite is suitable for the removal of $\mathrm{Pb}$ (II) ions from aqueous solutions. The prepared biocomposite can be considered as a new approach to improve the quality of the treated effluent and to clean up a polluted aqueous ecosystem.

Author Contributions: C. Gok and M. Kaygusuz conceived and designed the experiments; performed the experiments; analyzed the data and wrote the paper. Both author checked the final paper.

Funding: This study was financially supported by General Directorate of Agricultural Research and Policies (TAGEM) of Republic of Turkey Ministry of Food, Agriculture and Livestock under the project number of TAGEM 14-ARGE44.

Conflicts of Interest: The authors declare no conflict of interest.

\section{References}

1. Isaac R.A.; GilL.; CoopermanA.N.;HulmeK.; EddyB.; RuizM.; JacobsonK.; LarsonC.;PancorboO.C. Corrosion in drinking water distribution systems: A major contributor of copper and lead to wastewaters and effluents, Environ. Sci. Tech. 1997, 31: 3198-3203.

2. Aslan A.; Üzüm (Işık) N.O. Determining the heavy metal contents of natural and artificial upholstery leathers, Tekstil ve Konfeksiyon 2015, 25 (1): 33-37.

3. Mondal M.K. Removal of $\mathrm{Pb}(\mathrm{II})$ ions from aqueous solution using activated tea waste: Adsorption on a fixed-bed column, J. Environ. Manag. 2009, 90 (11): 3266-3271.

4. Ugurlu I.; Unver M.C.; DoganY. Determination and comparison of heavy metal accumulation level of Ficus carica bark and leaf samples in Artvin, Turkey, Oxid. Commun. 2016, 39: 765-775.

5. Aksoy U.; Can H.Z.; Hepaksoy S.; SahinN. Incir yetistiriciligi (Fig farming), Turkiye Tarımsal Arastırma Projesi Yayinlari 2001, Izmir, Turkey. (in Turkish).

6. Chmielewská E.; Sabová L.; Peterlik H.; Wu A. Batch-wise adsorption, SAXS and microscopic studies of zeolite pelletized with biopolymeric alginate, Brazilian J. Chem. Eng. 2011, 28 (01): 63-71.

7. Sarioglu M., Removal of ammonium from municipal wastewater using natural Turkish (Dogantepe) zeolite, Separ.P urif. Technol. 2005, 41, 1-11.

8. Navarro A.E.; Musaev H.; Serrano K.; Masud M.E. Adsorption kinetics of cobalt (II) ions onto alginate beads from aqueous solutions, J Earth SciClim Change 2014, 5(8): 223-228.

9. Langmuir I. The Adsorption of gases on plane surfaces of glass, mica and platinum. J. Amer. Chem. Soc. 1918, 40 (9): 1361-1403.

10. Freundlich H.(1906) Adsorption in solution, Zeitschrift Für Physikalische Chemie, 57: 384-410. 
11. Dubinin M.M.; Zaverina E.D.; Radushkevich L.V. Sorption and structure of active carbons I. adsorption of organic vapors, Zhurnal Fizicheskoi Khimii 1947, 21: 1351-62.

12. Boufi S.; Alila S. Modified cellulose fiber as a biosorbent for the organic pollutants. In: Kalia S, Averous L (eds) Biopolymers: biomedical and environmental applications, 1st edn. Wiley, New Jersey, USA, 2011 , pp.483-524.

13. Sharma S.; Pathania D.; Singh P. Preparation, characterization and $\mathrm{Cr}(\mathrm{VI})$ adsorption behaviour study of poly(acrylic acid) grafted Ficus carica bastfiber, Adv. Mat.Lett. 2013, 4(4): 271-276.

14. $\mathrm{Hu}$ J. Biosynthesis of $\mathrm{SnO} 2$ Nanoparticles by fig (Ficus carica) leaf extract for electrochemically determining $\mathrm{Hg}(\mathrm{II})$ in water samples, Int. J. Electrochem. Sci 2015., 10: 10668 - 10676.

15. Bayomi M.; Choi Y.S.; Christodoulides K.; Fathi P.; Ghodasara A.; Knazik J.et al Zeolite-loaded alginate-chitosan hydrogel beads as a topical hemostat, University of Maryland, College Park, MD , 2015, 20742-7011 (301): 314-1328.

16. Jena J.; Pradhan N.; Dash B.P.; Sukla L.B.; Panda P.K. Biosynthesis and characterization of silver nanoparticles using microalga Chlorococcum humicola and its antibacterial activity, Int. J.Nanomat. Biostructures 2013, 3(1): 1-8.

17. Kosa S.A.; Al-Zhrani G.; Salam M.A. Removal of heavy metals from aqueous solutions by multi-walled carbon nanotubes modified with 8-hydroxyquinoline, Chem. Eng. J. 2012, 181-182: 159-168.

18. Dabbagh R.; Moghaddam Z.A.; Ghafourian H. Removal of cobalt(II) ion from water by adsorption using intact and modified Ficus carica leaves as low-cost natural sorbent, Desalin. Water Treat. 2016, 57(42): 19890-19902.

19. Gok C. Neodymium and samarium recovery by magnetic nano-hydroxyapatite, J. Radioanal. Nucl. Chem. 2014, 301 (3): 641-51.

20. Bayramoglu G. Biosorption of heavy metal ions on immobilized white-rot fungus trametesversicolor, J. Haz. Mat. 2003, 101 (3): 285-300.

21. Aytas S.; Yurtlu M.; Donat R. Adsorption characteristic of U(VI) ion onto thermally activated bentonite, J. Haz. Mat. 2009, 172(2-3): 667-74.

22. Alfaro-Cuevas-Villanueva R.; Hidalgo-Vázquez A.R.; Cortés Penagos C.J.; Cortés-Martínez R. Thermodynamic, Kinetic, and Equilibrium Parameters for the Removal of Lead and Cadmium from Aqueous Solutions with Calcium Alginate Beads, The Scientific World Journal 2014, 2014:1-9.

23. Fiol N.; VillaescusaI.; Mart'inez M.; Miralles N.; Poch J.; Serarols J. Sorption of Pb(II), Ni(II), Cu(II) and Cd(II) from aqueous solution by olive stone waste, Sep. Purif. Tech. 2006, 50: 132-140.

24. Liang S.; Guo X.; Tian Q. Adsorption of Pb2+ and $\mathrm{Zn} 2+$ from aqueous solutions by sulfured orange peel, Desalination 2011, 275: 212-216.

25. Chen H.; Zhao J.; Dai G.; Wu J.; Yan H. Adsorption characteristics of $\mathrm{Pb}$ (II) from aqueous solution onto a natural biosorbent, fallen Cinnamomum camphora leaves, Desalination 2010, 262: 174-182.

26. Basu M.; Guha A.K.; Ray L. Biosorptive removal of lead by lentil husk, J. Environ. Chem. Eng. 2015, 3 (2): 1088-1095.

27. ] Matheickal J.T.; Yu Q. Biosorption of lead(II) and copper(II) from aqueous solutions by pre-treated biomass of Australian marine algae, Biores. Tech. 1999, 69: 223-229.

28. Amarasinghe B.M.W.P.K.; Williams R.A. Tea waste as a low-cost adsorbent for the removal of $\mathrm{Cu}$ and $\mathrm{Pb}$ from wastewater. Chem. Engin. J. 2007, 132: 299-309.

29. Gupta V.K.; Rastogi A. Biosorption of lead from aqueous solutions by green algae Spirogyra species: Kinetics and equilibrium studies, J. Haz. Mat. 2008, 152: 407-414.

30. Gupta V.K.; Pathania D.; Agarwal S.; Sharma S. Removal of Cr(VI) onto Ficus carica biosorbent from water, Environ. Sci. Pollut. Res. 2013, 20: 2632-2644.

31. Sasikala S.; Muthuraman G. Studies on adsorption of chromium (VI) onto Ficus carica seed from wastewater, Int. J. Recent Sci. Res. 2015, 6(3): 3100-3108. 